\title{
O saneamento básico e suas implicações no meio ambiente e na saúde humana
}

O saneamento básico é conceituado como um conjunto de serviços, infraestruturas e instalações operacionais direcionados à população. As instalações operacionais que compõem o saneamento básico são compostas por: distribuição de água potável, coleta e tratamento de esgoto, drenagem urbana e coleta de resíduos sólidos. Estes serviços influenciam diretamente na saúde, qualidade de vida e no desenvolvimento da sociedade como um todo. Assim, esta pesquisa teve como objetivo estudar a relação dos serviços de saneamento com o meio ambiente e com a saúde pública. A metodologia utilizada foi revisão bibliográfica do tipo descritiva com abordagem qualitativa. A amostra foi composta de artigos, monografia, periódicos publicados em revistas nacionais com data de publicação compreendida entre os últimos sete anos. A base de dados para levantamento dos artigos foram: Google Acadêmico; BIBENG (Biblioteca da Escola de Engenharia UFRGS), dentre outros. Os resultados demonstraram que ainda é grande o déficit no que diz respeito ao acesso ao saneamento básico a falta de acesso a esses serviços prejudicama saúde pública, especialmente das populações de baixa renda ou vulneráveis que vivem em periferias. Ao final concluiu-se que a relação dos serviços de saneamento com o meio ambiente e com a saúde pública é uma relação de interligação, onde o saneamento básico, quando realizada de maneira eficiente e completa favorece a elevação do nível da saúde pública, além de contribuir com a preservação do meio ambiente.

Palavras-chave: Saneamento Básico; Saúde Pública; Meio Ambiente.

\section{Basic sanitation and its implications for the environment and human health}

\begin{abstract}
Basic sanitation is conceptualized as a set of services, infrastructures and operational facilities directed to the population. The operational facilities that comprise basic sanitation are composed of: distribution of drinking water, collection and treatment of sewage, urban drainage and solid waste collection. These services directly influence health, quality of life and the development of society as a whole. Thus, this research aimed to study the relationship of sanitation services with the environment and public health. The methodology used was a descriptive bibliographic review with a qualitative approach. The sample consisted of articles, monograph, periodicals published in national magazines with publication date between the last seven years. The database for collecting the articles were: Google Scholar; BIBENG (UFRGS School of Engineering Library), among others. The results showed that there is still a large deficit with regard to access to basic sanitation; the lack of access to these services is detrimental to public health, especially for low-income or vulnerable populations living on the outskirts. In the end, it was concluded that the relationship of sanitation services with the environment and public health is an interconnection relationship, where basic sanitation, when carried out in an efficient and complete manner, favors an increase in the level of public health, in addition to contribute to the preservation of the environment.
\end{abstract}

Keywords: Basic Sanitation; Public health; Environment.

Topic: Engenharia Civil

Reviewed anonymously in the process of blind peer.
Received: 09/08/2020

Approved: $20 / \mathbf{1 1 / 2 0 2 0}$
Danielson Xavier da Silva (iD)

Universidade em Porto Nacional, Brasil

http://lattes.cnpq.br/9594503780048820

http://orcid.org/0000-0001-7750-2920

xavierdasilvadanielson@gmail.com
Referencing this:

SILVA, D. X.. O saneamento básico e suas implicações no meio ambiente e na saúde humana. Engineering Sciences, v.8, n.3, p.10-18, 2020. DOI: http://doi.org/10.6008/CBPC2318-3055.2020.003.0002 


\section{INTRODUÇÃO}

O Saneamento Básico, segundo a Organização Mundial de Saúde (OMS), pauta-se no controle de todos os fatores do meio físico do homem, que executam ou que podem executar efeitos positivos no que diz respeito ao bem-estar físico, mental e social. O saneamento é permeado por um conjunto de ações sobre o meio ambiente, que buscam alcançar a salubridade ambiental, através da implantação de serviços e infraestruturas que possuem a finalidade de prevenir doenças, melhorar a qualidade de vida dos indivíduos e por consequência promover a saúde das pessoas (MACIEL et al., 2015).

Para Santana (2014) o saneamento básico é responsável por promover o controle da saúde pública e por este motivo é de fundamental importância para o bem-estar do ser humano, uma vez que melhora a qualidade de vida de toda a população de um determinado local, eliminando fatores de risco à saúde pública e, por consequência, aumentando as condições sócio ambientais, que são favoráveis a uma boa sobrevivência. A qualidade de vida é possível quando o município trabalha com políticas públicas de implantação de saneamento básico, como os serviços de sistema de abastecimento de água, de esgoto, coleta, destino dos resíduos sólidos, dentre outros serviços que são vitais à vida do ser humano.

A Lei no 11.445/2007 estabelece diretrizes nacionais para o saneamento básico, além de esta política ser também assegurada na Constituição Federal brasileira. Essa lei é um instrumento de planejamento e de prestações de serviços que buscam garantir a saúde pública, porém essa garantia, em certas regiões, ainda é precária, o que tem provocado uma enorme desigualdade e déficit no processo de inserção, o que exige grandes investimentos e, desta maneira, uma melhoria básica nas condições de saneamento (LAZZARETTI, 2012).

Para que a sociedade tenha dignidade humana e condições essenciais à sobrevida de cada indivíduo, é necessário que a gestão pública garanta os serviços de saneamento básico, uma vez que a falta desta política tem provocado uma grande desigualdade social e isto acaba gerando uma grande injustiça social, retratada pelas desigualdades nos sérvios fornecidos (WAGNER, 2013).

Para Philippi Junior (2005) por meio do saneamento básico deve-se ofertar os seguintes serviços: esgotamento sanitário, abastecimento de água, limpeza urbana, manejo de resíduos sólidos, drenagem de água pluviais, controle de doenças transmissíveis, e demais serviços e obras especializadas, porém, atualmente, o saneamento básico está se resumindo apenas às quatro primeiras atividades.

Estima-se que mais de um bilhão de habitantes do planeta não possuem acesso à habitação segura e a serviços básicos. É importante destacar que o abastecimento de água insuficiente, condições ambientais precárias e sistemas de esgotos precários são os principais responsáveis pelo desenvolvimento de surtos de doenças e epidemias (MACIEL et al., 2015).

Sendo assim, pergunta-se: qual a relação entre os serviços de saneamento básico e as condições de vida da população? Como o saneamento básico pode contribuir para a diminuição dos agravos de saúde pública?

Para responder à problemática levantada, colocou-se como objetivo desta pesquisa estudar a relação 
dos serviços de saneamento com o meio ambiente e com a saúde pública.

\section{METODOLOGIA}

Esta pesquisa trata-se de um estudo secundário, uma vez que foi estabelecido conclusões a partir de estudos primários, que já foram publicados na literatura. Foi realizada uma revisão bibliográfica do tipo descritiva com abordagem qualitativa.

A pesquisa do tipo descritiva observa, registra e analisa fenômenos, sem manipulá-los. Procura descobrir a frequência, sua natureza, características e sua relação com outros fenômenos. A abordagem qualitativa se preocupa, com as ciências sociais, com um nível de realidade que não pode ser quantificado, apenas analisado e estudado (MINAYO, 2010).

Realizou-se um estudo retrospectivo, onde a amostra foi composta de artigos, monografia, periódicos publicados em revistas nacionais com data de publicação compreendida entre os últimos sete anos. A base de dados para levantamento dos artigos foram: Google Acadêmico; BIBENG (Biblioteca da Escola de Engenharia UFRGS), dentre outros.

Utilizou-se como critérios de inclusão publicações que possuíam data compreendida entre os anos de 2013 a 2019; que possuíam palavras chave como: saneamento básico; meio ambiente e saúde. Os critérios de exclusão pautaram-se publicações que tivessem data de publicação inferior ao ano de 2013, bem como aquelas publicações que não tivessem as palavras chaves acima descritas.

\section{DISCUSSÃO TEÓRICA}

\section{Saneamento Básico}

O saneamento básico é definido por Garcia et al. (2017) com um conjunto de medidas tem como objetivo modificar ou preservar o meio ambiente e suas condições com o intuito de prevenir doenças e promover a saúde, melhorando a qualidade de vida da toda a sociedade, além de incentivar que o indivíduo seja mais produtivo, facilitando, assim, a atividade econômica. O saneamento básico inclui serviços como: coleta e tratamento de esgoto, distribuição de água potável, coleta de resíduos sólidos e drenagem urbana.

O marco legal sobre o saneamento básico no Brasil se deu com a criação da Lei no 11.445 de 5 de janeiro de 2007, período esse que marcou o início de uma nova fase na gestão dos serviços públicos de saneamento básico. Essa lei prevê que todos os cidadãos brasileiros têm direito de acesso ao saneamento básico, porém, ainda existe um grande número de pessoas que não usufruem desse serviço. Nesta lei está estabelecido que os municípios brasileiros devem elaborar um Plano Municipal de Saneamento Básico para planejar os serviços de saneamento, além de determinar os princípios, obrigações, delegação dos serviços, regras e condições de retomada dos serviços (MACIEL et al., 2015).

Apesar de existir amparo legal para execução do saneamento básico em todo o país, sabe-se que ainda é grande o número de cidades que carecem desta política. Segundo o SNISำexiste no Brasil um total de

\footnotetext{
${ }^{1}$ Sistema Nacional de Informações sobre Saneamento 
1.531 municípios que não possuem sistema público de esgoto (MDR, 2019).Esses índices são preocupantes, uma vez que o saneamento básico é uma política pública que está diretamente relacionada com a manutenção da saúde pública.

A este respeito Prado et al. (2014) destacam que o Brasil é um país que possui grandes problemas de acesso aos serviços de saneamento básico, em especial quando se refere ao esgotamento sanitário. Os autores destacam ainda que ainda é grande o número de desigualdade de acesso aos serviços disponibilizados pelo saneamento básico, o que acaba provocando um impacto negativo à saúde pública, sendo que este problema é mais expressivo em populações de baixa renda ou vulneráveis, moradores de periferias.

Segundo informações do IBGE sobre as características gerais dos domicílios brasileiros no ano de 2018 , verificou-se que apenas $66,3 \%$ dos domicílios brasileiros possuem acesso à rede geral ou fossa ligada à rede geral de esgoto, sendo que o maior percentual está no sudeste $(88,6 \%)$ e os menores estavam no Norte $(21,8 \%)$ e Nordeste $(44,6 \%)$. No Brasil, no ano de 2018 , havia cerca de 72,4 milhões de moradores em domicílios não atendidos pela rede geral de esgoto. Quanto a coleta de lixo, o IBGE demonstrou que em 2018 haviam 20,1 milhões de pessoas sem nenhum tipo de acesso à coleta de lixo, sendo que destes, 10,5 milhões estão no Nordeste e 3,8 milhões na região Norte (IBGE, 2019).

Na pesquisa desenvolvida por Garcia et al. (2017), os autores destacam que do ponto de vista sanitário, o acesso à rede de esgoto evita a poluição do solo, dos mananciais, além de evitar contato dos insetos e vetores com os dejetos, conseguindo assim, controlar e prevenir doenças. Olhando para o lado econômico, o saneamento básico leva a uma diminuição das despesas com o tratamento de doenças evitáveis, reduz o custo do tratamento da água de abastecimento através da prevenção de poluição dos mananciais e controle da poluição das praias e locais de recreação.

Saucha et al. (2015) realizam uma pesquisa com objetivo de caracterizar as localidades hiperendêmicas para esquistossomose no estado de Pernambuco quanto às condições de saneamento e recomendar medidas de intervenção ambiental que favoreçam a sustentabilidade das ações de enfrentamento da doença. Assim, os autores constataram que as condições precárias de saneamento básico na região estudam contribuiu de maneira determinante para a manutenção da hiperendemicidade da esquistossomose nessas áreas.

\section{Saneamento Básico e meio ambiente}

Entende-se por meio ambiente tudo aquilo que é formado pelo ar, luz, temperatura, umidade, solo, água e sais minerais, sendo estes, fatores denominados de abióticos ou bióticos. Sabe-se que todos têm direito a um meio ambiente equilibrado, o que é essencial a uma boa qualidade de vida, e que é dever da coletividade e do poder público preservá-lo e defendê-lo, uma vez que o meio ambiente não é uma fonte inesgotável de recursos e por este motivo não se pode depredá-la incontrolavelmente para alavancar o consumismo. É necessário que exista uma relação harmoniosa e equilibrada entre homem e meio ambiente para evitar a sua degradação (FOLLADOR et al., 2015). 
As cidades e a urbanização têm produzido um ambiente altamente degradado e segregado, o que acaba afetando a qualidade de vida de toda uma população. A degradação ambiental é provocada através da devolução dos resíduos provenientes da urbanização para a natureza; poluição, tanto do ar, quanto da água e do solo; além de problemas provenientes da constante artificialização da natureza, o que acaba deixando a vegetação, os espaços verdes e as áreas permeáveis como elementos secundários na paisagem urbana. Outro problema é a grande desigualdade social no que diz respeito a distribuição de renda, o que torna a periferia um local carente de serviços urbanos básicos, como é o caso da falta de rede de esgoto, provocando o lançamento do esgoto a céu aberto e até mesmo em conexões clandestinas no sistema de águas pluviais e lançamento direto nos rios. A falta de disposição adequada e tratamento dos resíduos sólidos provocam sérios problemas ambientais (LIMA, 2013).

Borja (2014) destaca que ainda é um grande desafio no Brasil a garantia de acesso universal e de qualidade ao saneamento básico, uma vez que ainda é grande o déficit de acesso a água potável, coleta de lixo, rede de esgoto, dentre outros e que este déficit pode estar relacionado ao modo de produção capitalista, a exclusão social, a desigualdade e a baixa qualidade dos serviços. Em uma pesquisa realizada por Teixeira et al. (2018) o autor demonstrou que no ano de 2016 existiam 29,7\% de domicílios brasileiros sem suporte de qualquer tipo de serviço de esgotamento sanitário, o que representa 20,6 milhões de domićlios no Brasil. No que diz respeito a distribuição dessas residências por região $68,1 \%$ encontravam-se na região Norte; $47,7 \%$ no Nordeste; 8,6 no Sudeste; 33,5 no Sul e 44,4 no Centro-Oeste.

Verifica-se que ainda é grande o déficit no que diz respeito ao acesso ao saneamento básico e diante desse problema, Lisboa et al. (2013) destacam que é necessário que os governantes tomem ações de intervenção na defesa do meio ambiente, promoção da saúde pública e melhoria das condições sanitárias, especialmente nas áreas urbanas, onde há um maior número de população. Os autores destacam que é necessário implantar um bom planejamento municipal de saneamento que busque melhoria do atendimento dos serviços visto que o planejamento urbano nem sempre incorpora este setor em toda a sua complexidade.

Lima (2013) destaca que os serviços de saneamento básico são essenciais e envolvem preocupações relacionadas a qualidade de vida, saúde e com aspectos sanitários. Ressalta, ainda, que a implantação de serviços de saneamento básico deve ser norteada por um bom planejamento, devido aos impactos que podem ser gerados, quando implantados inadequadamente.

\section{Saneamento Básico e Saúde Pública}

Um dos fatores mais importantes da saúde, segundo o conceito de promoção de saúde proposto pela Organização Mundial de Saúde - OMS, na Conferência de Ottawa, são as condições ambientais, ou seja, quando se vive em um meio insalubre o mesmo pode transmitir diversas doenças. Porém esse problema pode ser minimizado, e até mesmo eliminado quando se usa, apropriadamente, os serviços de saneamento básico (MACIEL et al., 2015).

Para Prado et al. (2014) o Brasil a falta de acesso aos serviços de saneamento básico prejudica a saúde pública, especialmente nas populações de baixa renda ou vulneráveis que vivem em periferias. Saucha 
et al. (2015) destacam que em todo o mundo, a falta de acesso a água potável e a falta de saneamento e higiene são responsáveis por aproximadamente 1,9 milhões de mortes por ano e por 4,2\% da carga global de doenças, o que provoca um alto índice de internações.

Paiva e Souza (2018) desenvolveram uma pesquisa com o objetivo de avaliar a associação entre condições socioeconômicas, de saneamento básico e de cobertura por equipes de saúde da família (EqSF) sobre as internações por doenças de veiculação hídrica no Brasil e perceberam que as internações por doenças transmitidas pela água ocorrem em todo o Brasil, sendo que as regiões Norte e Nordeste apresentam maiores proporções, respondendo por cerca de $6 \%$ das hospitalizações totais nessas regiões. Os indicadores para doenças infectoparasitárias (DIP) e doenças relacionadas à poluição hídrica, por região brasileira, está representada na tabela 1.

Tabela 1: Indicadores de saúde para doenças infectoparasitárias (DIP) e doenças relacionadas à poluição hídrica. Brasil e grandes regiões, 2015.

\begin{tabular}{l|l|l|l|l|l|l}
\hline & \multicolumn{4}{l}{} & \multicolumn{3}{|l}{ Doenças relacionadas à poluição hídrica } \\
\hline & $\begin{array}{l}\text { Taxa de de } \\
\text { internação }\end{array}$ & $\begin{array}{l}\text { Proporção de } \\
\text { internações }\end{array}$ & $\begin{array}{l}\text { Proporção de } \\
\text { gastos }\end{array}$ & $\begin{array}{l}\text { Taxa } \\
\text { internação }\end{array}$ & $\begin{array}{l}\text { Proporção } \\
\text { internações }\end{array}$ & $\begin{array}{l}\text { Proporção de } \\
\text { gastos }\end{array}$ \\
\hline Brasil & 430,38 & 7,74 & 6,82 & 175,55 & 3,15 & 0,99 \\
\hline Norte & 690,32 & 11,67 & 8,93 & 358,09 & 6,05 & 2,88 \\
\hline Nordeste & 623,28 & 11,40 & 8,00 & 337,88 & 6,18 & 2,23 \\
\hline Sul & 353,11 & 5,34 & 5,21 & 114,45 & 1,73 & 0,48 \\
\hline Sudeste & 275,74 & 5,37 & 6,82 & 56,08 & 1,09 & 0,34 \\
\hline $\begin{array}{l}\text { Centro- } \\
\text { Oeste }\end{array}$ & 437,72 & 7,43 & 5,82 & 155,12 & 2,63 & 0,88 \\
\hline
\end{tabular}

Rasella (2013) destaca que a falta de saneamento básico se relaciona de forma direta à morbidade e à mortalidade das pessoas por diarreia no Brasil. $\mathrm{O}$ autor ressalta, ainda que o abastecimento de água potável ainda é um grande problema em comunidades carentes dos grandes centros urbanos e em áreas rurais do país. Assim, Leoneti et al. (2011) destaca que para se obter água potável ideal ao consumo humano é necessário "(...) o investimento em saneamento e no tratamento do esgoto sanitário, que é realizado por meio de estações e tratamento de esgoto que reproduzem, em um menor espaço e tempo, a capacidade de autodepuração dos cursos d'água".

As doenças relacionadas com a água foram descritas por um autor em 2018. O autor destacou o grupo de doenças, as formas de transmissão e as principais doenças, conforme demonstra a tabela 2.

Tabela 2: Descrição das doenças relacionadas à água.

\begin{tabular}{l|l|l}
\hline Grupo de doenças & Formas de transmissão & Principais doenças \\
\hline Transmitidas pela via feco-oral. & $\begin{array}{l}\text { O organismo patogênico (agente causador da } \\
\text { doença) é ingerido. }\end{array}$ & $\begin{array}{l}\text { Diarreias e disenterias; cóleras; giardíase; } \\
\text { amebíase; ascaridíase. }\end{array}$ \\
\hline $\begin{array}{l}\text { Controladas pela limpeza com a água } \\
\text { (associadas ao abastecimento de } \\
\text { água). }\end{array}$ & $\begin{array}{l}\text { A falta de água e a higiene pessoal } \\
\text { insuficiente criariam condições favoráveis } \\
\text { para sua disseminação. }\end{array}$ & $\begin{array}{l}\text { Infecções na pele e nos olhos, como } \\
\text { tracoma e o tifo relacionado com piolho } \\
\text { e a escabiose. }\end{array}$ \\
\hline $\begin{array}{l}\text { Transmitidas por vetores que se } \\
\text { relacionam com a água. }\end{array}$ & $\begin{array}{l}\text { As doenças são propagadas por insetos que } \\
\text { nascem na água ou picam perto dela. }\end{array}$ & $\begin{array}{l}\text { Malária; febre amarela; dengue. Filariose } \\
\text { (elefantíase). }\end{array}$ \\
\hline
\end{tabular}

As formas de prevenção das doenças relacionadas com a água, são: evitar o uso de fontes contaminadas e proteger e tratar a água de abastecimento; fornecer água em quantidade adequada e promover a higiene pessoal e doméstica; eliminar condições que possam favorecer criadouros de insetos 
transmissores de doenças.

Assim, percebe-se que a falta ou carência de serviços de saneamento básico em grande parte das regiões brasileiras acaba provocando o lançamento in natura de dejetos nos corpos hídricos, o que compromete a qualidade da água que abastece determinada população e assim, favorece o aparecimento de doenças que estão relacionadas a água. Quando não existem serviços de saneamento, ou quando o mesmo é ineficiente e/ou insuficiente, a qualidade de vida saudável da população fica inviabilizada. A convivência diária com esgoto a céu aberto coloca a população vulnerável a diversos tipos de infecções e doenças (TEIXEIRA et al., 2018).

A falta ou carência de um serviço completo de saneamento básico provoca sérios problemas relacionados à saúde pública, uma vez que torna determinado ambiente passível à proliferação de vetores de diversas doenças, além de poluírem o ar, do solo e das águas. Foi sintetizado informações importantes sobre doenças que se relacionam com a falta ou carência de esgoto sanitário, conforme demonstra a tabela 3.

Tabela 3: Doenças que se relacionam com a falta ou carência de esgoto sanitário.

\begin{tabular}{|c|c|c|}
\hline Grupo de doenças & Formas de transmissão & Principais doenças \\
\hline \multicolumn{3}{|c|}{ Doenças relacionadas com as fezes } \\
\hline $\begin{array}{l}\text { Feco-orais } \\
\text { bacterianas) }\end{array}$ & $\begin{array}{l}\text { Contato de pessoa para pessoa, quando não } \\
\text { se tem higiene pessoal doméstica adequada. }\end{array}$ & $\begin{array}{l}\text { Poliomielite; Hepatite tipo A; giardíase; disenteria } \\
\text { amebiana; diarreia por vírus. }\end{array}$ \\
\hline $\begin{array}{l}\text { Feco-orais } \\
\text { (bacterianas) }\end{array}$ & $\begin{array}{l}\text { Contato de pessoa para pessoa, ingestão e } \\
\text { contato com alimentos contaminados e } \\
\text { contato com fontes de águas contaminadas } \\
\text { pelas fezes. }\end{array}$ & $\begin{array}{l}\text { Febre tifoide; febre paratifoide; diarreias e disenterias } \\
\text { bacterianas, como a cólera. }\end{array}$ \\
\hline $\begin{array}{l}\text { Heilmintos } \\
\text { transmitidos pelo } \\
\text { solo. }\end{array}$ & $\begin{array}{l}\text { Ingestão de alimentos contaminados e } \\
\text { contato da pele com o solo. }\end{array}$ & $\begin{array}{l}\text { Ascaridíase } \quad \text { (lombriga); } \\
\text { ancilostomíase(amarelão). }\end{array}$ \\
\hline $\begin{array}{l}\text { Tênias (solitárias) na } \\
\text { carne de boi e de } \\
\text { porco. }\end{array}$ & $\begin{array}{l}\text { Ingestão de carne mal cozida de animais } \\
\text { infectados. }\end{array}$ & Teníase; cistircercose. \\
\hline $\begin{array}{l}\text { Helmintos } \\
\text { associados à água. }\end{array}$ & Contato da pele com água contaminada. & Esquistossomose. \\
\hline $\begin{array}{l}\text { Insetos vetores } \\
\text { relacionados com as } \\
\text { fezes. }\end{array}$ & $\begin{array}{l}\text { Procriação de insetos em locais } \\
\text { contaminados por fezes. }\end{array}$ & Filariose (elefantíase). \\
\hline \multicolumn{3}{|c|}{ Doenças relacionadas com o lixo e transmitidas por vetores } \\
\hline Rato & $\begin{array}{l}\text { Através da mordida, urina e fezes; e através } \\
\text { da pulga que vive no corpo do rato. }\end{array}$ & Peste bubônica; Tifo murino; Lepstospirose. \\
\hline Mosca & $\begin{array}{l}\text { Por via mecânica (através das asas, patas e } \\
\text { corpo); Através das fezes e saliva. }\end{array}$ & $\begin{array}{l}\text { Febre tifoide; Salmonelose; } \\
\text { Cólera; Amebíase; Disenteria; Giardíase. }\end{array}$ \\
\hline Mosquitos & Através da picada da fêmea. & Malária; Leishmaniose; Febre amarela; Dengue; Filariose. \\
\hline Baratas & $\begin{array}{l}\text { Por via mecânica (através da asas, patas e } \\
\text { corpo); } \\
\text { Através das fezes. }\end{array}$ & Febre tifoide; Cólera; Giardíase. \\
\hline Suínos & Pela ingestão de carne contaminada. & Cisticercose; Toxoplasmose; Triquinelose; Teníase. \\
\hline Aves & Através das fezes & Toxoplasmose. \\
\hline
\end{tabular}

As formas de prevenção destas doenças são: implantar sistema de abastecimento de água. Melhorar as instalações sanitárias; tratar os esgotos antes disposição no solo; combater insetos transmissores e controlar caramujos.

Teixeira et al. (2014) realizaram uma pesquisa que teve como objetivo desenvolver um estudo do impacto sobre a saúde pública das deficiências do saneamento básico no Brasil no período de 2001 a 2009 e 
constataram que os óbitos resultantes de doenças relacionadas ao saneamento básico inadequado corresponderam, em média, a 13.449 mortes por ano, ou seja, cerca de 1,31\% do total. As principais doenças, apontadas na respectiva pesquisa, que foram responsáveis pela maioria dos óbitos foram: dengue, diarreia, chagas e esquistossomose.

Desta maneira, ressalta-se que o saneamento básico é de suma importância para a saúde pública e para a qualidade ambiental, porém a universalização dos serviços ainda permanece em um patamar considerado incipiente, onde o Brasil precisa melhorar suas ações em prol do crescimento desta política no país, uma vez que o déficit dos serviços é incompatível para um país, que em 2012, passou a ser a 6a economia do mundo (BORJA, 2014).

\section{CONCLUSÕES}

Nesta pesquisa, concluiu-se que a relação dos serviços de saneamento com o meio ambiente e com a saúde pública é uma relação de interligação, onde o saneamento básico, quando realizada de maneira eficiente e completa favorece a elevação do nível da saúde pública, além de contribuir com a preservação do meio ambiente.

Percebeu-se que o saneamento básico é constituído por diversos serviços, como: coleta de lixo, tratamento e distribuição de água, drenagem pluvial, coleta e tratamento de esgoto. Esses serviços são essenciais para a salubridade ambiental e para a qualidade de vida e saúde da população, sendo que isso foi constatado observando as informações a respeito da mortalidade e acometimento por doenças provocadas pela ausência e/ou ineficiência desses serviços.

Assim, percebeu-se que mais estudos sobre saneamento básico são essenciais e importantes para que essas informações sejam cada vez mais atualizadas, além de sempre focar sobre a importância da implantação desta política pública nos municípios.

\section{REFERÊNCIAS}

BORJA, P. C.. Política Pública de saneamento básico: uma análise da recente experiência brasileira. Saúde Soc. São Paulo, v.23, n.2, p.432-447, 2014. DOI: http://doi.org/10.1590/S0104-12902014000200007

FOLLADOR, K.; PRADO, G. P.; PASSOS, M. G.; NOTHAFT, S. C. Saneamento Básico: meio ambiente e saúde. Revista UNINGÁ Review, v.23, n.1, p.24-28, 2015.

GARCIA, M. S. D.; FERREIRA, M. P.. Saneamento básico: meio ambiente e dignidade humana. Dignidade Re-Vista, v.2, n.3, p.12, 2017.

IBGE. Instituto Brasileiro de Geografia e Estatística. PNAD contínua: abastecimento de água aumenta no Centro-Oeste em 201, mas se mantém abaixo do patamar em 2016. Estatísticas Sociais. IBGE, 2019

LAZZARETTI, L.. Saneamento básico e sua influência sobre a saúde da população. Monografia (Especialização Gestão em Saúde) - Universidade Federal do Rio Grande do Sul, Porto Alegre, 2012.
LEONETI, A. B.; PRADO, E. L.; OLIVEIRA, S. V. W. B.. Saneamento básico no Brasil: considerações sobre investimentos e sustentabilidade para o século XXI. Revista de Administração Pública, Rio de Janeiro, v.45, n.2, p.331348, 2011.

LIMA, V.. Saneamento ambiental como indicador de análise da qualidade ambiental urbana. Caderno Prudentino de Geografia, Presidente Prudente, n.35, v.2, p.65-84, 2013.

LISBOA, S. S.; HELLER, L.; SILVEIRA, R. B.. Desafios do planejamento municipal de saneamento básico em municípios de pequeno porte: a percepção dos gestores Eng. Sanit. Ambient., v.18, n.4, p.341-348, 2013. DOI: http://doi.org/10.1590/S1413-41522013000400006

MACIEL, A. B. C.; FELIPE, J. A.; LIMA, Z. M. C.. Os problemas de saneamento e seus impactos sobre a saúde pública do município de Dona Inês/PB. OKARA: Geografia em Debate, v.9, n. 3, p. 524-541, 2015. 
MDR. Ministério do Desenvolvimento Regional. Secretaria Nacional de Saneamento. Sistema Nacional de Informações sobre Saneamento: 24음 Diagnóstico dos Serviços de Água e Esgotos - 2018. Brasília: MDR, 2019.

PHILIPPI JUNIOR, A.. Saneamento, saúde e ambiente: fundamentos para um desenvolvimento sustentável. Barueri: Manole, 2005.

PRADO, T.; MIAGOSTOVICH, M. P.. Virologia ambiental e saneamento no Brasil: uma revisão narrativa. Cad. Saúde Pública, Rio de Janeiro, v.30, n.7, p.1367-1378, 2014. DOI: http://dx.doi.org/10.1590/0102-311X00109213

RASELLA, D.. Impacto do Programa Água para Todos (PAT) sobre a morbi-mortalidade por diarreia em crianças do Estado da Bahia, Brasil. Cad. Saúde Pública, v.29, p.40-50, 2013. DOI: http://doi.org/10.1590/S0102$\underline{311 \times 2013000100006}$

SANTANA, H. B.. A importância do saneamento básico na área urbana do município de São João do Rio do Peixe/PB, com enfoque no esgotamento sanitário. Monografia (Licenciatura em Geografia) - Universidade Federal de Campina Grande, Cajazeiras, 2014.
SAUCHA, C. V. V.; SILVA, J. A. M.; AMORIM, L. B.. Condições de saneamento básico em áreas hiperendêmicas para esquistossomose no estado de Pernambuco em 2012. Epidemiol. Serv. Saúde, Brasília, v.24, n.3, p.497-506, 2015. DOI: http://doi.org/10.5123/S1679-49742015000300015

TEIXEIRA, J. C.; OLIVEIRA, G. S.; VIALI, A. M.; MUNIZ, S. S.. Estudo do impacto das deficiências de saneamento básico sobre a saúde pública no Brasil no período de 2001 a 2009. Eng. Sanit. Ambient., v.19, n.1, p.87-96, 2014.

TEIXEIRA, M. D. S.; BENTO, I. A. B.; CARVALHO, L. S.; CARVALHO, M. C. S.. Impactos sócio ambientais provenientes do esgotamento sanitário a céu aberto. Revista Brasileira de Gestão Ambiental e Sustentabilidade, v.5, n.11, p.849-858, 2018. DOI: http://doi.org/10.21438/rbgas.051104

WAGNER, V. R.. Saneamento básico: gestão de serviços de esgoto do município de Lagoa dos Três Cantos/RS. Monografia (Especialização em Gestão Pública) Universidade Federal de Santa Maria, Santa Maria, 2013.

A CBPC - Companhia Brasileira de Produção Científica (CNPJ: 11.221.422/0001-03) detém os direitos materiais desta publicação. Os direitos referem-se à publicação do trabalho em qualquer parte do mundo, incluindo os direitos às renovaç̃̃es, expansões e disseminações da contribuição, bem como outros direitos subsidiários. Todos os trabalhos publicados eletronicamente poderão posteriormente ser publicados em coletâneas impressas sob coordenação da Sustenere Publishing, da Companhia Brasileira de Produção Científica e seus parceiros autorizados. Os (as) autores (as) preservam os direitos autorais, mas não têm permissão para a publicação da contribuição em outro meio, impresso ou digital, em português ou em tradução. 